\title{
UN DOMINICANO EN EL COLEGIO DE NOBLES AMERICANOS DE GRANADA. FAMILIA Y GENEALOGÍA DE JUAN CLEMENTE MARTINEZ SAVIÑÓN.
}

\author{
MARIA MAGDALENA GUERRERO CANO \\ Universidad de Granada
}

Como en otras ocasiones, un personaje de nuestra historia común (1) me lleva a esa querida isla. Se trata de Juan Clemente Martínez Saviñón. Este muchacho fue el propuesto por la Real Audiencia para ocupar la plaza becada que en el Colegio de Nobles de Granada, correspondía a Santo Domingo.

La propuesta y su tramitación nos ha permitido acercarnos al personaje, a su entomo familiar y a las instituciones dominicanas que en ese momento funcionaban; ya que hubo que gestionar distintos documentos para demostrar la nobleza y limpieza de sangre que se requería, y conseguir la licencia y permiso para trasladarse a España.

\section{EL COLEGIO DE NOBLES AMERICANOS.}

De todos es sabido que el XVIII es un siglo de reformas en el que se intentan mejorar o solucionar cuestiones que se venían arrastrando desde antiguo. Unas seran afortunadas, otras conflictivas y otras no fraguarán. Entre éstas últimas se encuentra el intento de crear un "Colegio para Nobles Americanos en Granada» (2). Tema sobre el que estamos trabajando con la idea de sacar a la luz un próximo libro, y que nos ha dado pie para conocer como también La Española se embarcó en este proyecto.

La empresa no era disparatada puesto que de esta forma las clases mas elevadas de los Reinos de Indias se educarían en la Metrópolis, teniendo una formación más afín con las ideas que aquí corrían. Al mismo tiempo, con esta educación se lograba una relación próxima con la legislación e instituciones en funcionamiento y de las que con mucha probabilidad se podría pasar a formar parte; puesto que la normativa del Colegio preveía que al finalizar los estudios muchos antiguos alumnos desempañaran cargos de alto rango en la peninsula. En definitiva, se conseguía la conexión entre las clases más elevadas de ambos continentes que eran las más cercanas al monarca y de las que tradicionalente salían las personas señaladas para ocupar puestos prominentes.

La idea de dar educación exclusivista a los jovenes de clases elevadas ya había tenido plasmación en el «Real Seminario de Nobles» fundado en Madrid en 1725. En él, se matriculaban estudiantes de toda la peninsula y también tenían cabida los alumnos procedentes de Indias, pero raramente acudían a pesar de los intentos de Floridablanca para estimular este tipo de inscripciones. 
Según apunta Olaechea, puede que esta fuera la causa de que el proyecto de un «Colegio para Nobles Americanos»que presentó en 1789 el capuchino Montealegre fuera aceptado (3).

Como sede se eligió la ciudad de Granada, aunque habían sido propuestos otros muchos lugares que se habían ido descartando por distintas causas: frialdad del clima, distancia de los puertos, el mucho bullicio y concurso de extranjeros, o la proximidad a las distracciones y embelezos de la Corte. En la ciudad de la Alhambra se logró comprar al Cabildo de la Catedral un antiguo edificio que había correspondido al extinguido Colegio de Santa Catalina. Se valoró en 213.750 reales de vellón; aunque se aplazó el pago total, mediante una hipoteca al $3 \%$, lo que suponía 6.412 reales con 17 maravedís de rédito anual. Según la documentación describe:

«la planta de dicha casa se compone de ocho mil quinientos veinte y seis pies cuadrados y forma un cuadrilongo de tres cuerpos, de alzado de casi veinte (24v) varas de altura, con tres fachadas exentas a otras tantas calles».

El proyecto de Montealegre se pulió y reformó repetidamente a propuesta de Floridablanca, apareciendo, finalmente, la Real Cédula de Erección el 15 de enero de 1792 (4).

La Cédula estaba compuesta por 47 artículos que contemplaban distintos aspectos:

-En el Colegio se daría una «educación civil y literaria que havilitase a los alumnos a servir utilmente en la Iglesia, la Magistratura, la Milicia y los Empleos Políticos», es decir se impartiría Teología, Jurisprudencia Civil y Canónica, Arte Militar y Política; títulos que se considerarían de igual validez que los expedidos por cualquier Universidad. Se admitirían como colegiales a «los hijos y descendientes de puros Españoles nobles, nacidos en las Indias, y los de Ministros Togados, intendentes y oficiales Militares naturales de aquellos dominios, sin excluir a los hijos de Caciques e Indios nobles, ni los mestizos nobles» entre doce y diez y ocho años. Para ello había que dirigirse, en el caso de Santo Domingo, al Presidente de la Real Audiencia, a fin de pedir licencia y hacer las pruebas de nobleza o exhibir los respectivos títulos o patentes de los padres del pretendiente, además había que presentar certificados de salud expedidos por un médico y de latinidad por un maestro, excepto si se pretendían realizar estudios de Arte Militar.

-El Colegio se mantendría de los fondos de Temporalidades de Indias. No obstante se costearía por el Colegio la habilitación y embarque del primer joven que lo hiciera desde Santo Domingo. Igual prerrogativa se concedía a los primeros colegiales que vinieran de otros lugares. En el Colegio se becaría a veinte colegiales, cinco de cada una de las cuatro ramas de los estudios, otros veinte pagarían sólo 200 pesos fuertes al año, otros veinte sólo 300 pesos anuales y el resto, en número indeterminado, deberían pagar 400 pesos. Estas becas se 
conseguirían tras la demostración, en examen, del buen aprovechamiento en los estudios. Por parte del colegial serían los gastos de embarque y viaje hasta Granada y la ropa y utensilios que deberían llevar. En previsión de extraordinarios, el padre del futuro educando tendría que presentar «una escritura en que con las devidas solemnidades se asegurase el pago puntual de la porción o cüota.. que le corresponda en todo el tiempo de su educación».

-Los estudios serían de diez años y finalizados éstos, los jovenes deberían abandonar el centro, pero el Rey prometía atender «muy especialmente a los que hayan sido Colegiales para promoverlos a los empleos, y dignidades a que se muestren acreedores por su providad e instruccion segun las quatro clases de sus repectiva enseñanza».

- Los profesores y otros cargos serían designados por orden real.

-También se prefijaba la relación entre colegiales, los servicios y cuidados que se les prestarían, el tipo de comida, e incluso el uniforme:»El trage de los Colegiales sera uniforme en todo tiempo e igual en la forma al que usare la Nobleza en la Corte y Yo señalare; solo los Teologos usarán el vestido de Abate o el que en qualquiera epoca sea usual entre personas de su profesion. Por la Casa se suministrará a cada Colegial dos vestidos al año, uno de invierno y otro de verano, dos sombreros, seis pares de medias de seda, doce pares de zapatos, dos camisolas con buertas y otros tantos corbatines con cada vestido: una camisa de dormir y todas las demas menudencias necesarias para el aseo y el adorno de suerte que no necesiten les venga cosa alguna de fuera del Colegio para su verdadera comodidad o decencia».

Según la Real Orden de 22 de marzo de 1792 (5), la Real Cédula se distribuyó ampliamente en los Reinos de Indias y tuvo una acogida calurosa. Inmediatamente comienzan a ponerse en marcha los mecanismos para conseguir la entrada en el Colegio. Algunos expedientes para petición de becas son presentados con increible prontitud. Incluso en el mismo año de 1792 llegan a la peninsula algunos estudiantes que son acogidos en otros centros, porque en este asunto no se había hecho nada, tras comprar el edificio que se preveía dedicar a Colegio.

El gobierno de Santo Domingo acusa recibo de las instrucciones que prescriben la forma en que se ha de probar la nobleza, el 22 de junio. Por esas fechas Miguel Martinez de Venecia Santelizes comienza a gestionar ante la Real Audiencia, la admisión de su hijo Juan Clemente en el Colegio de Nobles Americanos; pero hay dificultades -sobre todo económicas- y hasta mayo de 1794 , la solicitud no tiene el visto bueno.

Para 1795 estaba claro que no había fondos para llevar a cabo el proyecto del Colegio, ni se preveían la llegada de nuevas remesas; por lo que el 27 de abril se da orden de enviar una Circular a las autoriadades de Indias en la que se les comunique la suspension definitiva del proyecto. El 7 de julio Joaquín Garcia, 
gobernador de Santo Domingo, acusa recibo de la orden, sus fundamentos y motivos, y se da por enterado para tenerla presente a fin de " no admitir por ahora hasta nueva orden las pretensiones dirigidas a entrar jovenes en el Colegio de Nobles Americanos de la ciudad de Granada, haciendolo saber a los sujetos que las promueven».

\section{JUAN CLEMENTE MARTÍNEZ SAVIÑÓN. UN DOMINICANO PROPUESTO PARA EL COLEGIO DE NOBLES AMERICANOS DE GRANADA.}

Como decimos más arriba, para ser admitido como colegial en Granada era necesario, junto con otros requisitos, demostrar limpieza de sangre y nobleza. La normativa para hacerlo se recogía en la «Instrucción en que se prescribe la forma en que han de hacerse las pruebas de limpieza de sangre y Nobleza de los que pretendan entrar en el Colegio de Nobles Americanos de la ciudad de Granada conforme al artículo $5^{\circ}$ de la Real cédula de erección» (6), que aunque fechada el 17 de enero, dos días despues de la Cédula de fundación, iba unida a ella.El documento estipulaba que:

$1^{\circ}$. Había que presentar la fe de bautismo del pretendiente, las de sus padres y la de casamiento de éstos legalizadas ante el Virrey, Presidente, Capitán General o Audiencia.

$2^{\circ}$. También se presentarían las informaciones que acreditaran la limpieza de sangre y nobleza de los padres y abuelos paternos y maternos del pretendiente, procedentes de donde fueran las familias, con citación judicial del Procurador Síndico y ante el Escribano del pueblo, autorizadas por tres escribanos del mismo o de otros pueblos, o en su falta por tres testigos que fueran nombrados por los jueces.

$3^{\circ}$. Los documentos que acompañaran a estas informaciones debían ser copias legalizadas de ejecutorias de hidalguía ganadas en tribunal competente. En su falta se debía presentar una certificación del Ayuntamiento Pleno, firmada por todos los vocales y Síndico que acreditara la nobleza del pretendiente y sus familiares. En última instancia sería valido un testimonio dado por auto de Juez en el que consten actos de nobleza de los ascendientes.

$4^{\circ}$. Las informaciones y documentos se examinarían por el Fiscal de la Audiencia o el Promotor-Fiscal que se nombrara, e informada la autoridad superior -Presidente de la Audiencia en este caso- se daría el correspondiente auto de aprobación.

Ajustandose a esta normativa, Miguel Martinez de Venecia Santelizes consiguió que su hijo Juan Clemente fuera propuesto para colegial becado en 
Granada (7). Gracias a las gestiones que tuvo que hacer y a la documentación que tuvo que presentar, hemos podido rastrear su vida y su genealogía familiar.

\section{Gestión de la plaza de colegial.}

Miguel Martinez creyó que a su hijo Juan Clemente se le ofrecía la oportunidad de su vida, por lo que agilizó cuanto pudo los trámites para presentar la documentación que se requería (8).

En pocos días reunió los documentos acreditativos y los presentó ante José Antonio de Urizar, Regente de la Real Audiencia, ya que en esas fechas el Presidente, Joaquín García, estaba fuera de Santo Domingo (9). Ajustándose a la normativa, éste los pasó al Fiscal que examinó los documentos e informaciones y sin encontrar reparo alguno, los evacuó el 22 de noviembre de 1792; aunque con la advertencia de que no había dinero (10) para financiar la habilitación y embarco de Juan Clemente, según se preveía que se hiciera con el primer joven que fuera de Santo Domingo en el artículo $8^{\circ}$ (11) de la Cédula de fundación. En consecuencia, pedía información de donde se podían sacar esos fondos. Esta fue la causa de que el expediante pasara al Acesor de la Capitanía para que buscara posibles soluciones. Durante siete meses se estuvo aplazando el asunto, pero el padre de Juan Clemente, Miguel Martinez, argumentado «el atrazo de su hijo en sus adelantamientos y carrera militar a que iba destinado", presionaba porque el tiempo pasaba sin posible solución.

Finalmente el 15 de junio de 1793 se expidió el auto librando la correspondiente licencia para que el muchacho se condujera a España; pero esto no era solución porque en el mismo auto se pedía información de donde saldría el dinero para los gastos que habían de generarse. Luego Juan Clemente tenía el permiso para viajar, pero no tenía medios para hacerlo. La situación «de hecho» poco había cambiado. Se apuntaba que por el artículo 46 (12) de la Cédula, todos los fondos que necesitara el Colegio saldrían del ramo de Temporalidades de Indias. Pero era el Colegio, no los colegiales. No obstante Miguel Martinez pide que con este fin se le adelanten 60 pesos. A cambio -aunque los 60 pesos no alcanzaban para ello- se ofrecía a pagar la ropa y utensilios que debía llevar el muchacho (Apendice 1) y el viaje de más de 60 leguas hasta Montecristi, que era donde tocaban los barcos-correos.Así conseguía: $1^{\circ}$ ) que no se demorara más el viaje; $2^{\circ}$ ) que aunque ponía unos 100 pesos de su bolsillo, esperaba que por Orden Real se los devolvieran. Si no era así, él los pagaría, de lo que ofrecía hacer fianza.

Ante este nuevo estado de cosas, el 13 de febrero de 1794 el Fiscal accede a entregar los 60 pesos que saldrían del ramo de Temporalidades, igual que el costo del viaje de Juan Clemente.

En la exposición de los hechos que posteriormente hizo el padre, argumentaba que se hizo así, porque el Fiscal 
«compadecese en su misma representación de el atrazo que havía padecido el pretendiente en su carrera y adelantamiento, con el justo nombre de Pobre pretendiente».

Lo que posteriormente sucedió no fue lo que se había previsto, porque a Miguel Martinez se le entregaron 150 pesos, de los que otorgó escritura de fianza; cantidad con la que debía costear la habilitación y el embarque, y sólo esto último suponía 125 pesos -45 por el transporte y 80 por la manutención- en el caso de el muchacho fuera considerado como militar, ya que a esa carrera iba destinado. Sólamente quedaban 25 pesos.

Dado el desarrollo que iban tomando los acontecimientos, el padre expone su penosa situación: sólo cuenta con 25 pesos para gastos, cuando realmente había gastado mucho más; tuvo que pagar la escritura de fianza, más de 50 pesos por los testimonios dados ante el Juez en los que consta la nobleza de los ascendientes, más de 200 pesos en los muebles de plata, ropas y demás utensilios que debe llevar Juan Clemente al Colegio. A lo que hay que añadir el costo del viaje por tierra hasta Montecristi. Para todo ello no le quedó más remedio que

«enagenarse de dos únicos criados que le acompañan, la una que le sirve de gizar y labar la ropa y el otro que le gana para su alimento y el de sus hijos».

Ante todo lo expuesto Miguel Martinez muesta su

«serena y segura confianza prometido desde luego en que la real benignidad de Vuestro generoso Real ánimo mirará por este infeliz Vazallo, mandando en su consequencia no solo se le suspenda la fianza en que esta constituido por razon de los ciento sinquenta pesos, sino tambien se le satisfagan y reintegren del predicho ramo, ó del que fuere de el agrado de V.M, quantos costos ha sufrido y espera sufrir, assi en los de la Abilitacion como en los de su embarque y demás para cuyo fin ha ido e irá aperciviendo resguardo de sus pagos, pues assi lo tiene V.M. dispuesto en el ya citado capitulo octavo».

Hasta aquí, todo lo alegado por Miguel Martinez tiene una argumentación lógica, pero a partir de este punto se dirige al Rey como un pobre súbdito, bascando su conmiseración y el reconocimiento de sus méritos. Alega como en el transcurso de los hechos se había quedado viudo

«le acaeció en este intermedio la fatal desgracia de haverle sobrevenido a su esposa una larga y lastimosa enfermedad, de la qual (que le duró por espacio de mas de cinco meses) huvo de fallecer de ella ....No es de este lugar el manifestar a V.M. el dolor, sentimiento, y aflicción de vuestro Vasallo al hallarse desprendido de su amada compañera, sus vienes cortos, y hallarse rodeado de seis hijos tan tiernos qe. solo cuenta doce años de edad el qe. se conduce al Colegio...», 
por lo que no ha podido descuidar el cuidado paternal que debe a sus hijos, dado que el mayor pretende ir a Granada, pero por su inocencia es aventurado enviarlo solo en el viaje. Propone como la mejor solución, acompañar a su hijo; y así podría pasar a Gudalajara y tomar posesión del «empleo» de Alguacil Mayor que disfrutó su padre, y cuyo derecho él había recibido por herencia. Dado que era Regidor de Santo Domingo, necesitaba contar con el permiso real para abandonar su cargo y trasladarse a la peninsula, lo que pedía que se le concediera y así poder

«lograr sobre todo el insaciable deseo y gozo qe. tiene de echarse a Vuestro Reales Pies' de donde espera la remuneración de los distinguidos meritos y servicios que hicieron sus mayores en aumento y defensa de la Monarquia».

Las misivas del Regente de la Audiencia de 22 de mayo, y de Miguel Martinez de 24 del mismo mes, vinieron a la peninsula en el mismo barco. En Santo Domingo se esperaba la resolución definitiva, cuando en realidad lo que llegó fue la Circular que suspendía definitivamente el proyecto. Pensamos que Juan Clemente y su familia no saldrían en ese momento de la isla, aunque no conocemos que sucedería poco después cuando, tras el tratado de Basilea y la ocupación francesa, muchos dominicanos se trasladaron a otras islas, sobre todo a Cuba (13).

«En el tratado de Paz...cede S.M. la parte que posee en esa Isla dejando libertad y el espacio de un año para que se retiren della las familias españolas con sus efectos y pertenencias, la justa consideración del Rey y su amor a tan fieles vasallos ha determinado para conservarlos bajo su protección y paternal abrigo que en la isla de Cuba se les dé un equivalente a las posesiones de que eran dueños en Santo domingo y que su transporte sea de cuenta de S.M.» (14).

\section{¿Quien era Juan Clemente Martínez Saviñón?.}

El Santo Domingo del siglo XVIII ya no era el próspero de la centuria del seiscientos. Sus clases altas no poseían el nivel de riqueza que se podía encontrar en el continente. Sólamente algunos ganaderos mentenían comercio -en muchas ocasiones ilegal- a través de la frontera de Haití, que producía algunos beneficios; y los cargos públicos -casi todos desempañados por peninsulares o criollos de primeras generaciones- tampoco representaban ingresos sustanciosos, dado el retrazo y la insuficiencia con que llegaba el «situado» (15).

A este último grupo corresponde la familia de Juan Clemente Martínez Saviñón (16). El muchacho que era el mayor de seis hermanos, había nacido el 23 de junio de 1781 y fue bautizado el 5 del mes siguiente en la catedral, siendo su padrino el presbítero Juan Quiñones, cura rector de Montecristi. Según los certificaciones que los médicos Agustín Marco Gilabert y Pedro Pablo Irigollen hicieron de su naturaleza para que pudiera entrar en el Colegio granadino, era de 
buena estatura, excelente salud, sin defecto físico, temperamento robusto y ágil para la carrera de las armas.

Sus padres, Miguel Jerónimo Martínez (17) y $\mathrm{M}^{\mathrm{a}}$ Antonia Saviñón (18)(Apendice 2), que eran las primeras generaciones estrictamente criollas de sus familias, se habían casado en Santo Domingo el 7 de agosto de 1780 (19), con 18 y 20 años respectivamente. Es posible que por la similitud de cargos en la administración o el ejército que desempañaron distintos miembros de las dos familias, ellos tuvieran una situación económica similar, también ambos poseían un cierto prestigio social y una cercana ascendencia española; todo ello favoreció que ambos grupos familiares se emparentaran mediante el matrimonio de Miguel y $\mathrm{M}^{\mathrm{a}}$ Antonia. Parece que cuando se casaron no gozaban una situación desahogada, porque según las manifestaciones de un vecino

«de la testamentaría de sus mayores ... no juzga que le haya cabido a mucho y que no sabe que tenga oficio más que el manejo de sus cortos bienes y la pequeña porción que había llevado la mujer al matrimonio, los cuales le contribuyen para lo preciso, pero no para el explendor y lustre con que lo hicieron sus antepasados».

Por lo que Miguel viendo que su familia aumentaba con el nacimiento de nuevos hijos y que los bienes eran escasos, se dispuso a buscar mayor prosperidad económica. Con este fin, en el año 1786 hizo dos intentos: consiguió el cargo de Regidor Perpetuo de Santo Domingo, y pleiteó porque el patronato de unas capellanías que habían fundado sus antepasados fuera adjudicado al mayor de sus hijos, Juan Clemente.

\section{Nombramiento como Regidor Perpetuo (20)}

Pedro Fernandez de Castro había sido nombrado como Regidor Vitalico el 14 de septiembre de 1766, pero estando enfermo, se vió incompetente para ejercer, por lo que renunció en el Rey el 4 de junio de 1784. Hasta el 19 de noviembre del año siguiente no se hizo el pregón admitiendo posturas para ocupar el cargo que quedó desierto. Poco después, el 18 de enero de 1786, se dispuso que la proclama apareciera en carteles que se pegaron por la ciudad. Pero el 3 de marzo hubo que retirarlos, sin que se hubiera ofrecido postura. El 3 de abril comparece Miguel Martinez y ofrece 500 pesos. Cantidad en la que es regulado el cargo por testigos y oficiales de la Real Hacienda. Por fin, el 6 de julio se hace la venta y remate por los señores de la Real Junta de Almoneda. El procedimiento era que un negro esclavo hiciera el pregón hasta las 11`30 h.; como a esta hora no se había mejorado la postura, el cargo de Regidor fue adjudicado a Miguel que contrajo la obligación de pagar a las Cajas Reales 519 pesos, 5 reales y 18 maravedises $(500$ p. que había ofrecido, 16 p., 5 r. y $11 \mathrm{~m}$. de la media annata y 2 p. 7 r. y $31 \mathrm{~m}$. por los fletes de conducción a los Reinos de Castilla. 
Pleito por el patronato de las capellanías.(Apendice 3).

Miguel Martínez tenía claro que su hijo era un niño pobre; por lo que con objeto de que dispusiera de algunos bienes, en 1786, pleiteó con su cuñado Joseph Arredondo, por el patronato de unas capellanías.

Los fundadores habían sido sus tíos abuelos Francisco y Gerónimo de Figueroa. Francisco había sido canónigo y Gerónimo que fue capitán de Infanteria, tuvo dos hijos:Lorenzo que fue presbítero y Francisco que murió sin hijos. Por lo que todos los derechos recayeron en Barbara de Figueroa, hermana de los fundadores y abuela de Miguel Martinez. Este alegaba que su hermana Isabel que recibía los beneficios del patronato, ya había sido mejorada por su abuela Barbara en 1/3 y 1/5 de la herencia, además estaba casada con Joseph Arredondo que ejercía de abogado acreditado de la Real Audiencia y Justicia Mayor de «los lugares de la isla», por lo que percibía un sueldo de 1.000 pesos anuales.

Sin embargo, él era

«un hombre pobre, sin más bienes que la cortedad que heredé de mis padres y abuelos, sin oficio alguno que me suministre lo necesario»

y el único varón descendiente legítimo, ya que sus hermanos Antonio y Alejandro habían muerto, por lo que hacía valer sus derechos.

Parece que no era el primer pleito en el que se ambarcaba Miguel Martinez, porque en las declaraciones de un testigo, Critóbal de Acuña, se expone como tenía

"mujer e hijos, que aunque pudiera estar acomodado, los muchos pleitos que han sobrevenido a la testamentaría de sus mayores han dejado el caudal en una porción muy corta».

Es posible que en las demás causas por las que pleiteó, obtuviera la misma sentencia que en ésta, que le fue denegada, porque su herman Isabel era de mayor edad y por tanto con más derechos para disfrutar del patronato de las capellanías, ya que no estaba estipulado que se primara a los varones.

\section{Ascendencia paterna (Apendice 4).}

El abuelo paterno de Juan Clemente fue Manuel Martinez de Mendoza. Era natural de Guadalajara, donde ejerció el cargo de Aguacíl Mayor; también había sido agregado a una de las Secretarías del Despacho Universal de Indias.

Llegó a Santo Domingo en torno a 1751, con el sequito del Gobernador Francisco Rubio Peñaranda (21), de la que también formaban parte sus compañeros y amigos Pedro Jirón que era teniente coronel graduado, y Pedro 
Madrigal que iba como oficial mayor de la Real Contaduría. Rubio Peñaranda lo estimó muy particularmente, igual que su esposa Josefa de Godar que el día de su boda con Margarita Venezia Santelices, le ragaló el vestido a la novia. Encontrandose enfermo viajó a la peninsula, donde permaneció hasta finales de 1758, en que la Casa de Contratación le dió licencia para pasar a Santo Domingo en el pingue San Severo de la Real Compañía de Barcelona, especificando

«no ser de los prohibidos a pasar a las Indias...que son los que van sin oficio ni licencia...» (22).

Manuel Martinez que era considerado como sujeto muy distinguido por su nacimiento, modales y comportamiento; podía acreditar limpieza de sangre y tenía escudo de armas que exponía publicamente en su casa (23);

«...son personas distinguidas y nobles, limpias de toda mala raza de moro, judio ni de penitenciados por ningun tribual de los recien convertidos a Nuestra Santa Fe, que ninguno ha ejercido oficio servil ni mecanico...» (24)

Su hermana Isabel Martinez que fue religiosa en el convento de Santo Domingo el Real de Toledo, había renunciado a la dote al profesar, por lo que toda la herencia recayó en Manuel.

Ambos eran hijos de Francisco Martinez de Mendoza, natural de Guadalajara y Administrador General de Rentas Reales en la ciudad de Toledo y theniente cuadrillero Mayor elegido por la Junta de los Alcaides de la Santa Hermandad Vieja de aquella ciudad, y de Antonia de Caro, natural de Orihuela; nieto por vía paterna de Francisco Martinez de Mendoza y de María de Magro, ambos naturales de Guadalajara, y por vía materna del murciano Antonio de Caro (25).

La abuela paterna fue Margarita de Venecia Santelizes, hija del Tesorero del Tribunal de Cruzada Miguel de Venecia Santelizes y de Barbara de Figueroa.

Miguel de Venecia (26) era hijo del matrimonio (27) formado por su homónimo Miguel de Venecia Santelizes (28) y Manuela Andrea Piero de Verdad; nieto por vía paterna del matrimonio (29) formado por el theniente de Mar y Guerra en las Reales Armadas a cuyo servicio falleció, Miguel de Venezia -a su vez hijo de Sebastian de Venecia y de Francisca de Coto- y por Mariana de Santelizes (30)-hija de Juan de Santelizes y de María de Erice-, y por vía materna de Felipe de Piero y Ana de Verdad. Todos

«fueron habidos, tenidos y distinguidos en esta mensionada villa (La Puebla de Escalante en Santander) en el tiempo que vivieron confiriendoles a cada uno en sus respectivos tiempos los oficios onorificos que se comunican a las primeras personas de calidad y nobleza de esta mencinada villa, conduciendo a los actos públicos como tales y de la primera distinción, como es notorio» (31). 
Los Santelizes entroncaban con los condes de Oñate, cuyo título fue otorgado por Enrique IV a D. Iñigo Velez de Guevara en 1469 (32).

Bárbara de Figueroa era hija del sargento Mayor de Santo Domingo Francisco de Figueroa Balcarcel, natural de Galicia, y de Isabel Rodriguez, descendiente de Diego Rodriguez y cuya ascendencia se remonta hasta el quinto abuelo Cristóbal Morales.En las probanzas se pone de manifiesto como de la «Ilustre Casa de Figueroa» descendían los Condes de Feria, cuyo título otorgó Enrique IV a Lorenzo Suarez de Figueroa; y estaban emparentados con los duques de Medina-Sidonia, Badajoz, Arcos, Alba, Infantado y Sesa, con los marqueses de Priego y Elche, y con los condes de Trastamara y Oropesa (33).

\section{Ascendencia materna (Apendice 5).}

Los abuelos maternos de Juan Clemente Martinez Savínón fueron Gregorio Saviñón (34) y Micaela Antonia de Tapia. Gregorio que era hidalgo de las «primeras familias de Canarias», llegó desde Cuba a Santo Domingo, donde ostentaba el cargo de Regidor de la ciudad en suplencia del Decano del Ayuntamiento, a la vez que ejercía otros empleos.

Micaela Antonia de Tapia era hija del canario Pedro de Tapia, que aunque

«no obtuvo empleo político o militar, comunmente por sus paisanos y el público fue reputado y tenido por hombre de distinción»(35)

y de Ana de Castro, nieta por vía materna de Gonzalo de Castro y Coronado que tenía reconocida «nobleza pública».

Hermanos de Micaela Antonia de Tapia fueron Francisco, el Regidor más antiguo del Ayuntamiento, y Jerónima que estuvo casada con Joaquín Puello Uriez, Alcalde Mayor de Santiago de los Caballeros e hijo del Regente Mayor de la Audiencia Andrés Puello.

Gregorio y Micaela Antonia además de su hija $\mathrm{M}^{\mathbf{a}}$. Antonia, la madre de nuestro Juan Clemente, tuvieron a Jacinta que estuvo casada con Fernando Mauleón, Tesorero oficial de las Cajas Reales; a Juana 'que se casó con el Teniente de Ingenieros Pedro Roig y Luis; a Ramón y a Francisco de Paula. Respecto a ellos nos dice la documentación

«que sus ascendientes por ambas lineas y los demás individuos contenidos ... octienen los encargos y empleos que expresan y han sido tenidos en tal reputación...desde tiempo inmemorial» (36). 


\section{NOTAS.}

(1) Andrés Alegret y Mesa; publicado en Memoria médico-topográfica de la isla de Santo Domingo (1864) por el médico Andrés Alegret y Mesa. En «Dynamis», Granada, 1987-1988, pags. 367-412. D. Bienvenido Monzón Martín, publicado en Disciplina y laxitud: la Iglesia dominicana en la época de la anexión, Servicio de Publicaciones de la Universidad de Cádiz, Cádiz, 1989; y El Arzobispo Monzón, serie «Hombres de Iglesia», nº 7, Santo Domingo, 1991. Fray Fernando Portillo y Torres, publicado en La ocupación de Santo Domingo por Saint Dominique a través de la correspondencia de su arzobispo, en «Les Revolutions Ibériques et Ibéroaméricaines a l' aube du XIXe siécle», Centre National de la Recherche Scientifique. Centre Regional de publication de Bourdeaux, 1991, págs. 313-340. En otros trabajos hemos hecho alusión a otros muchos personajes.

(2) La documentación procede del Archivo general de Indias (en adelante AGI), Indiferente General, prioritariamente en los legajos 1619, 1620 y 1621. Cuando no sea asî́ o en el caso de un documento significativo, lo señalaremos explícitamente. El tema ha sido tratado por varios autores en diversos artículos: BAREA FERRER, José Luis, El palacio de Carlos $V$ y el proyecto de su conversión en Colegio Militar de Nobles Americanos, en «Anuario de Historia Moderna y Contemporánea», Universidad de Granada, 1977-1978, $\mathrm{n}^{\circ} 4$ y 5 , págs. 27-49. DIAZ TRECHUELO LOPEZ-ESPINOLA, María Lourdes, Españoles Americanos en los Colegios Mayores del sacromonte y de San Bartolomé y Santiago de la Universidad de Granada. Siglos XVIII y XIX, en «Quinto Congreso Internacional de Historia de América», Publicaciones de la Comisión Nacional del Sesquicentenario de la Independencia del Perú, Lima, 1972, págs. 497-534, KONETZKE, Richard, Die Gründug des Real Colegio de Nobles Americanos in der Stadt Granada, en «Homenaje a J. Vicens», Madrid, CSIC, 1962-1963, págs. 647-653. OLAECHEA, Juan B., El Real Colegio de Nobles Americanos de Granada, en «Missionalia Hispanica», Madrid, CSIC, mayo-agosto 1963, año XX, nº 59, págs. 211-237.

\section{(3) OLAECHEA...}

(4) Real Cédula por la qual su Magestad funda un colegio de Nobles Americanos en la ciudad de Granada. AGI, Indiferente General, leg. 1620.

(5) Real Orden para la publicación de la Real Cédula de fundación del Colegio de Nobles Americanos de Granada, Ibidem.

(6) El artículo $5^{\mathrm{a}}$ de la Real Cédula decía: «ante los mismos Virreyes, Presidentes, Capitanes Generales y Audiencias se harán las pruebas de nobleza en la forma que se prevendrá e instrucción separada, se exhibirán», IBIDEM.

(7) En el trabajo de María Lourdes Díaz-Trechuelo citado más arriba, encontramos noticias de otro dominicano que se educó en Granada, en el colegio 
de San Bartolomé y Santiago. Se trata de José María Guillelmi y Valenzuela del que da noticia que nació en Santo Domingo el 25 de mayo de 1785 e ingresó en el Colegio granadino en 1785. Sus padres: D. Juan Guillelmi, natural de Sevilla, brigadier de los reales ejércitos, caballero de la Orden de Santiago. Casó con $D^{a}$ María Valenzuela, natural de la villa de Oropesa. Abuelos paternos: D. Lorenzo Nicolás Guillemi, natural de Bruselas, del Consejo de S.M. y su secretario. Melchora Clara de Andrada y Vandervilde. Abuelos maternos: D. Juan de Valenzuela, natural de Torrelaguna, caballero de la Orden de Alcántara, hijo del conde de la Puebla de los Valles, casó con D. Eugenio Maellas, natural de la villa de Bustar Viejo (Castilla la Nueva).

El padre D. Juan Guillelmí desempeñó varios cargos en Indias: comandante de artillería de la isla Española; gobernador de Campeche, teniente de rey de la plaza de La Habana; inspector general de las tropas de la isla de Cuba; capitán general de Caracas y presidente de aquella audiencia. Intendente de ejército de Caracas curante cuatro años. Promovido a Brigadier de los reales ejércitos, fue nombrado comandante general de la plaza de Ayamonte, costa de Poniente, y de las tropas acantonadas en ella con motivo de la guerra con Francia.

Otros antepasados ilustres: por la línea materna, el cardenal Cisneros y don Melchor de Liñán, obispo y arzobispo de Lima. Por la línea paterna, D. Antonio Guillelmí, gobernador de la plaza de Puerto Cabello (Venezuela). Estudios realizados: Primer año Lógica y Etica, segundo año, Jurisprudencia Civil, tercer año, Derecho canónico.

(8) Certificado pleno del M. Ilustre Cabildo, Justicia y Regimiento, despachado a fabor de D. Miguel Martz. de Venencia Santelizes y Figueroa. Año de 1780, AGI. Ultramar, leg. 1621.

(9) A través de la documentación tenemos noticia de que, para estas fechas, el capitán General y Presidente de la Audiencia dominicana estaba en la «frontera», lo que coincide con lo que dice el historiador García. GARCIA, José Gabriel, Compendio de la Historia de Santo Domingo, tomo I, quinta edición, impreso por Central de Libros, C. por A. Santo Domingo, R.D. 1982, pág. 242.

(10) En este tiempo las únicas entradas que tenía la Española eran el contrabando y el situado que llegaba «mal, tarde y nunca».

(11) Art. 8. No obstante, se costeará enteramente por cuenta de los fondos del Colegio la habilitación y embarco de los dos primeros jóvenes que a él vengan de cada uno de los Virreinatos de Nueva España, Perú, Santa Fe y Provincias del Río de la Plata, y de uno de los primeros que se envíen, respectivamente, de los reinos de Guatemala, Quito y Chile, las provincias de Caracas, Yucatán y Luisiana, y las Islas Española, de Cuba, Puerto Rico y Filipinas. 
(12) Art. 46. Para la subsistencia del establecimiento asignaré fondos suficientes en los ramos que tenga $\mathrm{Yo}$ a bien determinar en adelante, y, desde luego, destino el de Temporalidades de Indias, que desde los principios tengo aplicada a objetos de utilidad pública, para que de él se costee (como ya se ha hecho con una casa comprada en Granada para este establecimiento) todo cuanto el Colegio necesite en su erección y en los gastos de edificio, su extensión, ornato, muebles y demás, pues nada deseo tanto como ver logrado este establecimiento, para que mis amados vasallos de ambas Américas e Islas Filipinas reconozcan el desvelo que me debe la instrucción de sus hijos, a fin de abrirles por este medio las puertas para entrar en las distinguidas carreras de mi Real Servicio, en donde puedan adquirir la gloria con que imiten a sus mayores, e ilustren más y más a sus casas y familias.

(13) DEIVE, Carlos Esteban: Las emigraciones dominicanas a Cuba (17951808), Fundación Cultural Dominicana, santo Domingo, R.D. 1989. Documentos sobre la evacuación de la Isla de Santo Domingo, en «Boletín del Archivo Nacional», La Habana, XLVIII, enero-diciembre, 1949. LUGO LOBATON, Ramón, El tratado de Basilea, en «BAGN», Ciudad Trujillo, R.D., $\mathrm{XIV}, \mathrm{n}^{\circ}$ 68, enero-marzo 1951, págs. 86-119. BATTLE, Manuel Arturo, El tratado de Basilea. Desnacionalización del Santo Domingo español, Cuadernos de Interpretación Histórica, I, Ciudad Trujillo, R.D., 1951.

(14) AGI, Estado, leg. 17, 8-IX-1795.

(15) MARTIN REBOLO, J.F. Isabelo, Ejército y sociedad en las Antillas en el siglo XVIII, Ministerio de Defensa, Secretaría General Técnica, Sevilla, 1988, págs. 111-114.

(16) Diligencias promovidas por el Cavallero Regidor D. Miguel Martz. de Venecía Santelizes y Figueroa, para remitir a su hijo D. Clemente el Colegio de Nobles de Granada, en virtud de los documentos que acompaña. Año de 1792. AGI, Indiferente, leg. 1621.

(17) Miguel Jerónimo Martínez de Venecia Santelizes y Figueroa nació el 3 de marzo de 1762, y fue bautizado de urgencia, en su casa por el presbítero $D$. Juan Martínez, ejerciendo de padrino el capitán Pedro Girón. la ceremonia oficial tuvo lugar en la catedral el día 20, de manos del canónigo Juan José Aponte. Libro $7^{\circ}$ de Bautismos, hoja 445, Ibidem.

(18) $M^{a}$ Antonia Saviñón y Tapia había nacido en Santo Domingo el 16 de junio de 1760 y bautizada el día 28, por el franciscano Fr. Francisco Puertas, ejerciendo de padrino Andrés Megías, libro $7^{2}$ de Bautismos, hoja 339, Ibidem.

(19) El sr. Juez Provisor y Vicario General Licenciado D. Felipe José de Tres Palacios, canónigo de la catedral, autorizó el matrimonio que contrajeron Miguel Martínez y $\mathrm{M}^{\mathrm{a}}$ Antonia Daviñón, libro $6^{\circ}$ de Matrimonios, hoja 163 , Ibidem. 
(20) Origen, armas, hidalguía y nobleza de D. Miguel marz. de Venecia Santelizes para obtener uno de los Oficios de Regidor de esta ciudad de Santo Domingo, año de 1786, AGI, Indiferente General, leg. 1723, y Mapas y Planos (Escudos y Arvoles), 113 bis, 114 bis y 115 bis.

(21) GARCIA, Obra citada, págs. 198 y siguientes.

(22) Licencia a favor de D. Manuel Martínez de Mendoza, natural de la ciudad de Guadalajara, en los reinos de España, por los señores Presidente y Oidores del Tribunal y Real Audiencia de la Casa de Contratación de las Indias, año de 1758, AGI, Indiferente General, leg. 1621.

(23) Entre las pruebas que se presentaron en 1780 ante el Gobierno y Capitanía General de Santo Domingo para justificar la nobleza de Manuel Martínez de Mendoza, estuvieron las declaraciones de siete testigos que lo conocieron y trataron, fueron su primo hermano Francisco Caro; Andrés de Lecanda, Guardalmacén y Factor Principal de la Real Renta de Tabacos de Santo Domingo; Pedro Madrigal, Oficial mayor de la Real Contaduría, José Jacinto Ramírez, Relator de la ciudad de Santo Domingo y Chanciller Mayor, Andrés de Heredia, Teniente Coronel y Sargento Mayor del batallón fijo; Agustín Jirón, Ayudante Mayor y Capitán Graduado que era hijo de Pedro Jirón, uno de los compañeros que vinieron con Manuel Martínez en el séquito de Rubio Peñaranda. Justificación producida por D. Miguel Martz. de Venecia y Santelizes sobre su elgitimidad, Nobleza y Calidades de su persona, ante el Superior Govierno y Capitania Gral. de esta capital de Santo Domingo, año de 1780 , Ibidem.

(24) Ibidem.

(25) Antonio Caro estuvo empleado en la secretaría del padre de $D^{\circ}$ Josefa de Godar, esposa de Rubio Peñaranda. Ibidem.

(26) El clérigo José del Castillo bautizó a Miguel Venecia el 16 de agosto de 1699, ejerciendo de padrinos su abuelo Miguel de Venecia y María de Pendueca. Libro de Bautismos que principia el 4 de marzo de 1677 y ultima el 22 de febrero de 1711. Hoja 227v. IBIDEM.

(27) Miguel de Venecia Santelizes y manuela de Pierto se casaron el 27 de diciembre de 1694. Libro de matrimonios que principia el 4 de junio de 1650 y ultima el 25 de abril de 1707. Hoja 163. IBIDEM.

(28) El presbítero Juan Ruiz bautizó a Miguel de Venecia Santelizes el 24 de junio de 1664, ejerciendo de padrinos José de Joca y Seledonia de Valazco. Libro de Bautismos que principia el 26 de agosto de 1650 y se ultima el 13 de julio de 1665 . Hoja 667 . Ibidem. 
(29) Miguel de Venecia y Mariana de Santelices se casaron el 24 de septiembre de 1662 . Hoja 36v. Ibidem.

(30) Mariana de Santelices fue bautizada el 15 de enero de 1636, en su casa por estar en peligro de muerte. Fueron sus padrinos Juan Arredondo e Isabel Velasquez. Libro de Bautismos que principia el 6 de mayo de 1619 y ultima el 27 de enero de 1636 de la Santa Iglesia Colegial de Santander. Hoja 103. IBIDEM.

(31) Justificación plenisima donde consta la Limpiesa de Sangre, Hidalguia y Nobleza de Don Miguel de Venecia y Santelizes, Natural de la villa de Santander, Arzobispado de Burgos, hecha dha. justificación por mandado de Su Magestad y Señores de su Real y Supremo Conssejo de Castilla, con todas las Solemnidades necesarias para la probavilidad y calificacion. Año de 1739. IBIDEM.

(32) Origen, Armas, Hidalguia y Nobleza de D. Miguel de Venecia Santelices, natural de la villa de Santander, Arzobispado de Burgos; y por Quaderno separado consta la plenisima Justificación echa a este fin por mandado de S.M. y señores de su Real y Supremo Conssejo de Castilla. Año de 1739. IBIDEM.

(33) Origen, Armas, Hidalguía y Nobleza de Don Francisco de Figueroa Sargento Mayor de la Plaza de Santo Domingo y natural de Galicia. Año de 1738. IBIDEM.

(34) El apellido Saviñón lo encontramos repetidamente en el Santo Domingo de la época; casi todos eran militares de origen canario y respondían a los nombres de Nicolás, José, manuel, Alejandro, Pedro y Juan. GUTIERREZ ESCUDERO, Antonio, Un canario en la Española. Vida, hechos y familia de Pedro Lousel Montero, 1724-1801, en «V Coloquio de Historia Canario-Americana» (1982), I.1, Cabildo Insular de Gran canaria, 1985, págs. 165-202.

(35) Certificatos despachados por el M. Iltre. Cabildo, Justicia y Regimiento; a fabor de la calidad y Nobleza de Dn. Ramón y $D^{\circ}$ Jacinta Saviñón y Tapia, AGI, Indiferente General, leg. 1621.

(36) IBIDEM. 
Apendice 1: .

LISTA DE LOS UTENSILIOS Y ROPA OUE DEBERAN TRAER AL COLECIO DE NOBLES AMERICANOS DE LA CLUDAD DE GRANADA LOS INDIVIDUUSS DESTINADOS A EL.

Un baul

Una palargana, de metal

Una escribanía

Un cubierto de plata completo con la cifra de su nombre y apellido, y un vaso de plata con la misma cifra. Una xícara

Dos peynes, uno escarpidor y el otro espeso de marfil

Dos capillos, uno de ropa y otro de zapatos $y$ botas

In par de tixeras, un corcaplumas, y un palillero

Dos batas, una de bayeta blanca para el invierno, y otra de mahón para el verano. Doce camisolas de bueltas lisas, y no han de usarse otras con otros tancos corbatines.

Dos camisas lisas para dormir

Seis pares de calzetas con pie entero

Seis pares de calzoncillos

Seis pares de medias de seda

Dos pares de zapatos

Doce pariuelos, ocho de color y quatro blancos

Quatro sabanas de catre, $y$ quatro fundas para almohada Uria manta

Seis servilletas

Quatro toallas

Dos peinadores

EFECTOS OUF FRECISAMAENTE SE HAN DE FACER EN GRANADA PARA OUE SEAN UNIFORMES.

Un vestido de invierno o de verano, segun la estacion en que entre el colegial, el qual ha de ser presisamente de paño o de lona. Un espadín

un par de evilias

Un catre

Dos colchones

Und colcha

Un cubrecama

Dos gorros de dormir

Un estante en su mesa para libros

Una cortina para la alcoba

ADVERTENCIAS.

1) Al tiempo de retirarse del Colegio se llevaran los colegiales los muebies que huvieron traido en el estado en que se hallen.

2) Ia ropa blanca ha de señalarse con la respectiva cifra del colegial; $Y$ ae ella $Y$ de todos los dernas utensilios se ha de oasar una prolija revista haciendose el

correspondiente asiento en libro que al incento havra en la inspeccion de policia del Colegio.

31) Los estuches para las Maremazicas, los floretes para la esgrime, ei violín o qualquiera otro instrumento de misica, y el calzón de ante, botas y chupa de picadero se costearan por cuenza de los interesados.

Apendice. 2.

Familia de Juan clemente Martinez Saviñón

Miguel Gerónimo Martinez Ma Antonia Savizón
de Venecia Santelizes (3)
Y Tapia(2)
Y otros clemente Martinez Saviñón(i)

cinco hermanos 
spendice 3.

Gencalogía Dara reclamar el patronato de las canellanias

Francisco Isabel

de Figueroa Rodriguez

$\begin{array}{cc}\text { Miguel de venecia } & \text { Barbara, Francisco } y \text { Gerómino } \\ \text { Santelices } & \text { de Figueroa } \\ \text { Manuel Martinez de Mendoza Margarita de venecia } & \text { Santelizes }\end{array}$

Miguel Gerónimo Martinez de Vanecia Santelices

Apendice 4.

Ascendencia paterna.

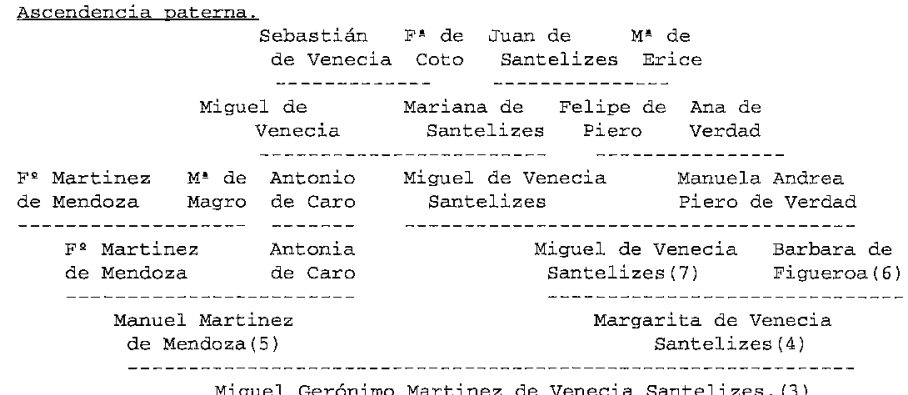

Miguel Gerónimo Martinez de Venecia Santelizes. (3)

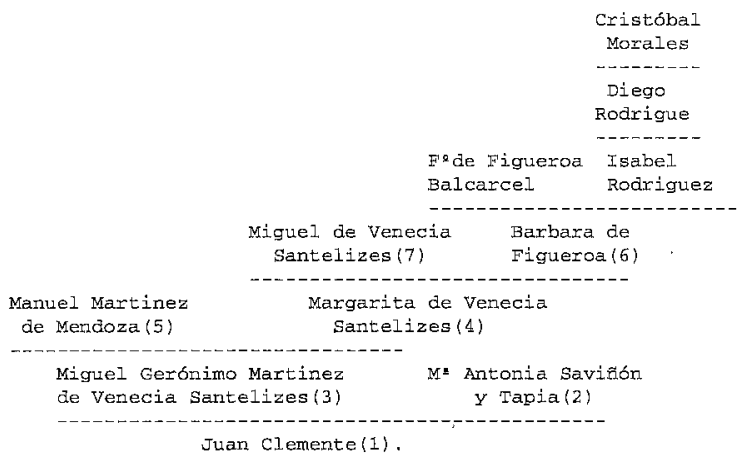

Apendice 5 .

Ascendencia materna.

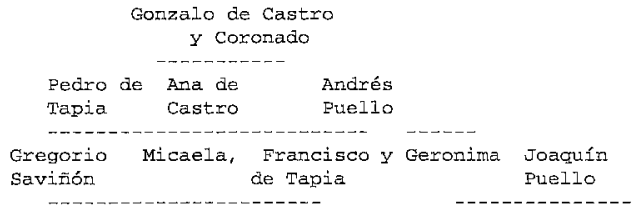

Migel Gerónimo M Artonia (2), Jacinta, Juana, Ramón

Mart. de Venecia y Francisco Savirión de Tapia

Santelices (3)

Juan Clemente ( 1 ) 